\title{
Comparison of Kidney-Ureter-Bladder Radiography with Computed Tomography Scout Film for the Diagnosis of Renal Calculi Taking Axial Computed Tomography as Gold Standard
}

\author{
Naila Iftikhar ${ }^{1}$, Sarah Maryam ${ }^{1}$, Abdul Rauf $^{2}$, Mehreen Fatima $^{1}$, Sultan Ayaz ${ }^{3, *}$, Syed Amir Gilani ${ }^{1}$, Raham \\ Bacha $^{1}$
}

${ }^{1}$ University Institute of Radiological Sciences \& Medical Imaging Technology. Faulty of Allied health Sciences, The University of Lahore, Lahore, Pakistan.

${ }^{2}$ Consultant Radiologist, Faisal Hospital Faisalabad, Pakistan.

${ }^{3}$ Directorate of Medical Sciences, GC University Faisalabad, Pakistan.

\section{Authors' Contributions \\ 1 Data Collection \& Processing, Data Analysis and/or Interpretation, Drafting of Manuscript. 2 Conception \& Study Design, Data Analysis and/or Interpretation, Critical Review. \\ 3 Conception \& Study Design, Data Collection $\&$ Processing \\ 4 Drafting of Manuscript, Critical Review. 5 Data Analysis and/or Interpretation, Drafting of Manuscript, Critical Review. \\ 6 Data Collection \& Processing, Critical \\ Review. \\ 7 Data Collection \& Processing, Critical Review.}

\begin{tabular}{l}
\hline Acknowledgement \\
\hline Article info. \\
Received: November 11, 2020 \\
Accepted: January 26, 2021 \\
\hline Funding Source: Nil \\
Conflict of Interest: Nil \\
\hline Cite this article: Iftikhar N, Maryam S, Rauf A, \\
Fatima M, Ayaz S, Gilani SA, Bacha R. \\
Comparison of Kidney-Ureter-Bladder \\
Radiography with Computed Tomography \\
Scout Film for the Diagnosis of Renal Calculi \\
Taking Axial Computed Tomography as Gold \\
Standard. RADS J Pharm Pharm Sci. 2020; \\
8(4):194-199.
\end{tabular}

*Address of Correspondence Author: ayaz_libra@hotmail.com

\begin{abstract}
A B STRACT
Background: Nephrolithiasis is a widespread disease with an incidence of 17-13 in North American, 5-9\% in Europe, and 1-5\% in the Asian continent. Plain abdominal radiography is used to visualize renal stones, but the cysteine stones are often poorly visible, uric acid and mixed stones are not visible at all. The second diagnostic tool for the diagnosis of renal calculus is computed tomography. The CT scout film is often overlooked and did not use for the diagnostic purpose.
\end{abstract}

Objective: To compare Kidney-ureter-bladder radiography with computed tomography scout film for the diagnosis of renal calculi taking axial computed tomography as a gold standard.

Materials and Methods: It was a cross-sectional analytical study design conducted on 57 patients presenting with acute flank pain in Faisal Hospital Faisalabad. Patients having ages between 18-60 were included in the study. Pregnant patients and patients with Indinavir therapy were excluded from the study.

Results: The sensitivity recorded for CT scout film was $66.7 \%$ and for the plain abdominal radiography was $80.7 \%$. The calculus carrying Hounse field unit less than $200 \mathrm{HU}$ were not visualized on both the modalities $\mathrm{x}$-ray and plain abdominal radiography. However, the calculus greater than $5 \mathrm{~mm}$ in size has a sensitivity of $73 \%$ on CT scout film.

Conclusion: The sensitivity recorded for CT scout film was $66.7 \%$ and for the plain abdominal radiography was $80.7 \%$. The calculus carrying Hounse field unit less than $200 \mathrm{HU}$ were not visualized on both the modalities $\mathrm{x}$-ray and plain abdominal radiography. However, the calculus greater than $5 \mathrm{~mm}$ in size has a sensitivity of $73 \%$ on CT scout film.

Keywords: CT scout, CT scan, x-ray KU. 


\section{INTRODUCTION}

Renal stone mostly present as acute renal colic from loin to groin pain. Sometimes stone size and its location enables the easy removal of stones from the body without any surgical intervention. To make a diagnosis alone based on physical examination and clinical manifestations is difficult [1]. Initial diagnosis for nephrolithiasis includes plain KUB x-ray [2]. It requires $\mathrm{x}$-rays with anterior-posterior orientation of the body starting from xiphisternum to symphysis pubis [3], [4]. It uses the same fundamental concept as Computed tomography but in a single plane. Because this imaging method visualizes calculus from only one direction so its accuracy is reduced, which results in a decrease specificity and sensitivity. Plain abdominal radiography is used to visualize many stones but cysteine stones are often poorly visible as compared to uric acid and mixed stones are not visible at all [5]. To solve this problem, usually the plain abdominal radiography is joined with ultrasonography to detect the renal stones, however overlying bowel gas and fecal material can easily hide the calculus. Furthermore, the radiography of KidneyUreter- Bladder cannot visualize the radiolucent stones thus limiting the diagnostic value of plain $\mathrm{x}$-ray. However, in some patients, a KUB x-ray is enough for diagnosing the exact shape, location, and size of the calculus. The main advantage of KUB x-ray is that it is a useful examination for the follow-up of known radiopaque calculus and requires less time to perform KUB even for the ambulant patients [6].

\section{OBJECTIVE(S)}

To compare Kidney-ureter-bladder radiography with computed tomography scout film for the diagnosis of renal calculi taking axial computed tomography as gold standard.

\section{METHODOLOGY}

\section{Study Design}

It was a cross-sectional study and the sample size was 57 patients.

\section{Study Location}

After taking informed consent, data were collected from patients presenting with renal pain in the Urology diagnostic section of Faisal hospital Faisalabad Pakistan through developed questionnaire and compiled data collection sheets according to the questionnaire variables (age, gender, occupation, side, location, $x$-ray findings, CT scout findings, CT axial findings, stone size in $\mathrm{mm}$, hounse field unit).

\section{Duration of Study}

It was a $9^{\text {th }}$-month study.

\section{Statistical Analysis}

Collected data was analyzed through spss version 23 . Inclusion criteria were both genders presenting with clinical suspicion of renal stones and between the ages of $18-60$ years. Exclusion criteria included pregnant patients and patients on Indinavir therapy. Ethical approval of the study was taken from the ethical review board University of Lahore.

\section{RESULTS}

A total of 57 patients who visited Faisal Hospital Faisalabad and meeting the inclusion and exclusion criteria were included in this study. Out of 57 patients, $36(63.2 \%)$ were male and $21(36.8 \%)$ were female patients with a mean age of 42 (Table 1). Altogether 57 stones were detected by CT scan with a mean stone size of $7.9 \mathrm{~mm}$. The study showed that the male gender was predominant in the case of urolithiasis as shown in the table. All the stones appeared positive on CT axial images which were already taken as gold standard.

Table 1. Showing Ratio of Male and Female.

\begin{tabular}{|c|c|c|}
\hline & Frequency & Percent \\
\hline Male & 36 & 63.2 \\
\hline Female & 21 & 36.8 \\
\hline Total & 57 & 100.0 \\
\hline
\end{tabular}

\section{Prevalence of Renal Calculus Among Different Occupations}

From these 57 patients, different occupation was analyzed for renal stones and it has been noted that house wives have a greater ratio of renal stones as compared to other professions. The least no of renal stones were noted in medical professionals. The following table and graph shows the prevalence of urolithiasis among different occupations (Table 2, Figure 1). 
Table 2. Showing Prevalence of Renal Calculus Among Different Occupation.

\begin{tabular}{|c|c|c|c|}
\hline Name of occupations & Frequency & Percent & Valid Percent \\
\hline Govt Employ & 8 & 14.0 & 14.0 \\
\hline Teacher & 9 & 15.8 & 15.8 \\
\hline Student & 10 & 17.5 & 17.5 \\
\hline Worker & 9 & 15.8 & 15.8 \\
\hline House Wife & 11 & 19.3 & 19.3 \\
\hline Shop Keeper & 8 & 14.0 & 14.0 \\
\hline Dr & 2 & 3.5 & 3.5 \\
\hline Total & 57 & 100.0 & 100.0 \\
\hline
\end{tabular}

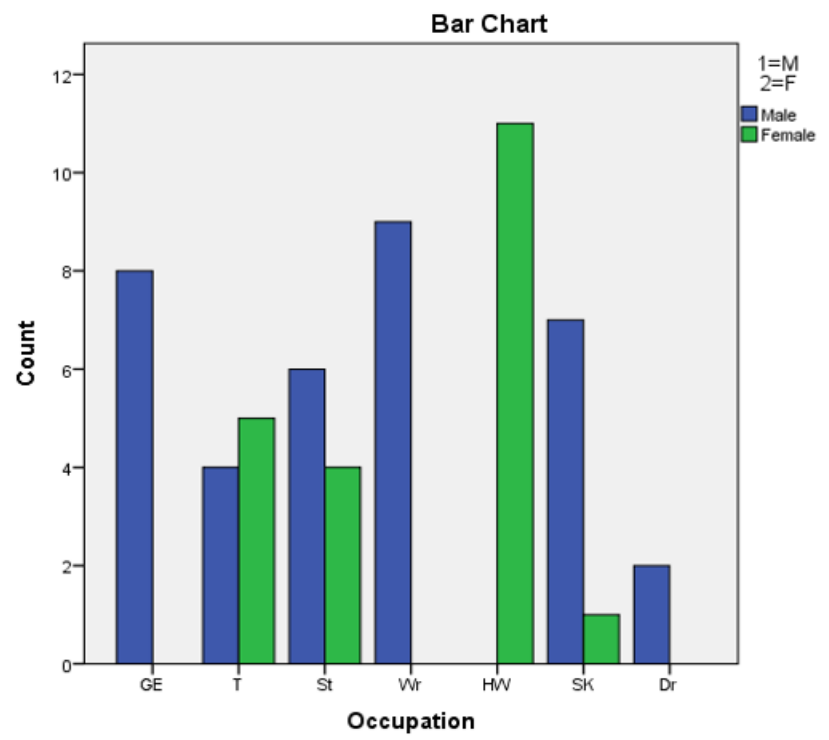

Figure 1. Showing prevalence of renal calculus among different Occupations.
Sensitivity of Abdominal Radiography at Different Locations in the Renal System

Cross Tabulation of the results between plain $\mathrm{x}$-ray findings with the location of calculus in the renal system showed that the stones which were present in proximal ureter, were seen positive on plain abdominal radiography with a sensitivity of $19.3 \%$. Ureterovesical junction encountered 5 stones, out of which $4(7.0 \%)$ stones were positive on plain abdominal x-ray and 1 (1.8\%) stones appeared negative on plain abdominal $x$-ray. Mid ureter had 2 stones and both appeared positive on plain abdominal x-ray with a sensitivity of $3.5 \%$. In Kidneys $28(49.1 \%)$ were seen positive on plain abdominal $x$ ray while $7(12.3 \%)$ stones were negative on plain abdominal x-ray. Distal ureter encountered 11(19.3\%) stones, out of which $8(14.0 \%)$ stones were X-ray positive and $3(5.3 \%)$ stones were $x$-ray negative. The detail of stone visibility on plain abdominal $x$-ray is shown below (Table 3).

Table 3. Showing Sensitivity of X-ray Abdominal Radiography at Different Locations in the Renal system

\begin{tabular}{|c|c|c|c|c|c|}
\hline \multirow{2}{*}{\multicolumn{3}{|c|}{ Location of the renal stone }} & \multicolumn{2}{|c|}{ Xray Finding } & \multirow{3}{*}{$\begin{array}{c}\text { Total } \\
11\end{array}$} \\
\hline & & & Positive & Negative & \\
\hline \multirow{10}{*}{ Location } & \multirow{2}{*}{ PU } & Count & 11 & 0 & \\
\hline & & $\%$ of Total & $19.3 \%$ & $0.0 \%$ & $19.3 \%$ \\
\hline & \multirow{2}{*}{ UVJ } & Count & 4 & 1 & 5 \\
\hline & & $\%$ of Total & $7.0 \%$ & $1.8 \%$ & $8.8 \%$ \\
\hline & \multirow{2}{*}{ MidU } & Count & 2 & 0 & 2 \\
\hline & & $\%$ of Total & $3.5 \%$ & $0.0 \%$ & $3.5 \%$ \\
\hline & \multirow{2}{*}{ Kidney } & Count & 21 & 7 & 28 \\
\hline & & $\%$ of Total & $36.8 \%$ & $12.3 \%$ & $49.1 \%$ \\
\hline & \multirow{2}{*}{ DU } & Count & 8 & 3 & 11 \\
\hline & & $\%$ of Total & $14.0 \%$ & $5.3 \%$ & $19.3 \%$ \\
\hline \multirow{2}{*}{\multicolumn{2}{|c|}{ Total }} & Count & 46 & 11 & 57 \\
\hline & & $\%$ of Total & $80.7 \%$ & $19.3 \%$ & $100.0 \%$ \\
\hline
\end{tabular}


Sensitivity of CT Scout Film at Different Locations in the Renal System

At the proximal ureter, 8 out of 11 stones with a sensitivity of (14.0\%) were seen as positive and 3 out of $11(5.3 \%)$ stones appeared negative on CT scout film. At mid ureter 2 stones were noted, 1 (1.8\%) appeared positive on CT scout film and 1 (1.8\%) appeared negative on CT scout film. Kidneys had a total of 28 stones, out of which $18(31.6 \%)$ stoned appeared positive on CT scout film and 10 (17.5\%) appeared negative on CT scout film. Ureterovesical junction had $5(8.8 \%)$ stones, out of which 4 (7.0) stones appeared positive on CT scout film and 1 $(1.8 \%)$ stone appeared negative on CT scout film. The distal ureter had 11 stones, out of which 7 (12.3\%) stones appeared positive on CT scout film and $4(7.0 \%)$ stones appeared negative on CT scout film (Table 4).

Table 4. Showing Sensitivity of CT Scout Film at Different Locations in the Renal System.

\begin{tabular}{|c|c|c|c|c|c|}
\hline \multirow{2}{*}{\multicolumn{3}{|c|}{ Location Wise Distribution in a Urinary System }} & \multicolumn{2}{|c|}{ CT scout finding } & \multirow{3}{*}{$\begin{array}{c}\text { Total } \\
11\end{array}$} \\
\hline & & & Positive & Negative & \\
\hline \multirow{10}{*}{ Location } & \multirow{2}{*}{ PU } & Count & 8 & 3 & \\
\hline & & $\%$ of Total & $14.0 \%$ & $5.3 \%$ & $19.3 \%$ \\
\hline & \multirow{2}{*}{ UVJ } & Count & 4 & 1 & 5 \\
\hline & & $\%$ of Total & $7.0 \%$ & $1.8 \%$ & $8.8 \%$ \\
\hline & \multirow{2}{*}{ MidU } & Count & 1 & 1 & 2 \\
\hline & & $\%$ of Total & $1.8 \%$ & $1.8 \%$ & $3.5 \%$ \\
\hline & \multirow{2}{*}{ Kidney } & Count & 18 & 10 & 28 \\
\hline & & $\%$ of Total & $31.6 \%$ & $17.5 \%$ & $49.1 \%$ \\
\hline & \multirow{2}{*}{ DU } & Count & 7 & 4 & 11 \\
\hline & & $\%$ of Total & $12.3 \%$ & $7.0 \%$ & $19.3 \%$ \\
\hline \multirow{2}{*}{\multicolumn{2}{|c|}{ Total }} & Count & 38 & 19 & 57 \\
\hline & & $\%$ of Total & $66.7 \%$ & $33.3 \%$ & $100.0 \%$ \\
\hline
\end{tabular}

Sensitivity of Abdominal Radiography with Respect to Stone Size

In this study, 11 stones were noted having size less than $5 \mathrm{~mm}$ and 46 stones were noted having size greater than $5 \mathrm{~mm}$. Out of these 11 smaller stones, 6 stones appeared positive on plain $\mathrm{x}$-ray radiography and 5 become radiolucent (negative) shown in (Table 5).

Table 5. Showing Sensitivity of X-Ray Abdominal Radiography with Respect to Stone Size.

\begin{tabular}{|c|c|c|c|}
\hline \multirow{2}{*}{ Stone Size } & \multicolumn{2}{|c|}{ Xray Finding } & \multirow{2}{*}{ Total } \\
\cline { 2 - 4 } & Positive & Negative & \\
\hline Less than 5 & $6(54 \%)$ & $5(45 \%)$ & 11 \\
\hline Greater than 5 & $40(86.7 \%)$ & $6(13 \%)$ & 46 \\
\hline Total & 46 & 11 & 57 \\
\hline
\end{tabular}

Sensitivity of CT Scout Film with Respect to Stone Size

Out of 11 stones which were noted less than $5 \mathrm{~mm}$ in size, 4 appeared positive on CT scout film while 7 remained undetected on CT scout film (Table 6).

Table 6. Showing Sensitivity of CT Scout Film with Respect to Stone Size.

\begin{tabular}{|c|c|c|c|}
\hline \multirow{2}{*}{ Stone Size } & \multicolumn{2}{|c|}{ CT Scout Finding } & \multirow{2}{*}{ Total } \\
\cline { 2 - 3 } & Positive & Negative & \\
\hline Less than 5 & $4(36.3 \%)$ & $7(63.6 \%)$ & 11 \\
\hline Greater than 5 & $34(73 \%)$ & $12(26 \%)$ & 46 \\
\hline Total & 38 & 19 & 57 \\
\hline
\end{tabular}




\section{DISCUSSION}

Non-contrast Computed tomography now a days has been used widely for the diagnosis of renal calculi. When calculus is diagnosed, patient must be treated appropriately depending upon the calculus size and location and symptoms of the patient [7],[8]. If a patient will not recover from the symptoms, radiological evidence is necessary for the follow up which confirms the status of the kidneys and ensure that they are not at risk for further silent obstructions [9],[10]. So it is important that the radiological modality is reliable for the diagnosis and follow up scans. Ultrasound is a noninvasive radiological modality and can be used but its sensitivity is (10$50 \%$ ) for the renal calculus which is low. Intravenous urography can be used but it has a disadvantage of a risk of allergy due to contrast media [11]. Conventional abdominal plain radiography has been used for many years for the diagnosis of renal calculi. However, bowl gases, bones, and costal cartilage may interfere with the diagnosis and obscure the margins of the kidney. In addition to all these many other structures such as arterial calcification, calcified lymph nodes, stool, abdominal and pelvic masses may also mimic the renal calculus for their location and appearance. Yap et al conducted a study and concludes that the sensitivity of plain film radiography is up to $73 \%$ [12]. As computed tomography has the advantage of its accuracy, speed, and safety. From the cases received while comparing the literality noted right side of the patients contains 20 (40.4\%) while the left side of the patient contains 34 (59.6\%) no. of calculus. Calculus was also described based on their location that is the kidney, Proximal Ureter, Distal Ureter, and ureterovesical junction. Number of positive cases on plan abdominal radiography and CT scout film at proximal ureter were $19.3 \%$ and $14 \%$, mid ureter were $3.5 \%$ and $1.8 \%$, distal ureter were $14 \%$ and $12.3 \%$, ureterovesical junction contains the same that is $7 \%$ and the kidney contain the positive cases of $36.8 \%$ and $31.6 \%$ respectively. Majority of the calculi were noted in the kidneys with a sensitivity of $48.1 \%$. All the calculi which were positive on CT scout film were also seen positive on Plain abdominal radiography. My study showed that no. of positive cases on plain abdominal radiography and CT scout film were 46/57 (80.7\%) and 38/57 (66.7\%) respectively. No. of positive cases noticed on CT scout film also appeared positive on x-ray radiography. The results noted in my study are closer to the results noted by Michael E. According to Michael $E$ the sensitivity of plain radiography was $77.4 \%$ and for CT scout radiography was $58.06 \%$ with a sample size of 110[13]. My results are higher in percentage noted by Yap. According to his study, the no. of positive cases on plain abdominal radiography were $73 \%$ and for CT scout films were 52\% [3]. Somehow little difference in study was due to the small sample size of my study. A total of 11 stones were noted whose size was less than $5 \mathrm{~mm}$. 4 stones from these were seen positive on CT scout films and 7 stones were seen negative on CT scout films. 46 Stones were detected larger than $5 \mathrm{~mm}$, out of which 34 stones were seen positive on CT scout film and 12 stones were seen negative on CT scout film. The sensitivity of stones less than $5 \mathrm{~mm}$ on CT Scout film was $36.3 \%$ and for the stones greater than $5 \mathrm{~mm}$ was $73 \%$. These results are closer to the sensitivity measured by G.EGE et al. According to his study the sensitivity of CT scout film larger than $5 \mathrm{~mm}$ were $66 \%$ [13]. Assi et al also supported my study in the case of stones greater than $3 \mathrm{~mm}$. According to his study number of positive cases on CT scout films for the stones larger than $3 \mathrm{~mm}$ were $81 \%$ and for abdominal radiography were $86 \%$ [7].

\section{CONCLUSION}

The CT scout radiography was found similar to plain radiography in the detection of renal calculi. However, the results indicated that $\mathrm{CT}$ scout radiography, carry significant potential to report calculi larger than $5 \mathrm{~mm}$, and its sensitivity for the calculus larger than $5 \mathrm{~mm}$ was reported as $73 \%$. CT scout radiograph should be considered as a baseline investigation for the diagnosis of renal calculus.

\section{LIMITATION(S)}

Shortcomings of the study include small sample size and confinement to only one hospital of Faisalabad.

\section{REFERENCES}

1. Pinduli I, Spivacow R, Del Valle E, Vidal S, Negri $\mathrm{AL}$, Previgliano $\mathrm{H}$, et al. Prevalence of urolithiasis in the autonomous city of Buenos Aires, Argentina. Urological research. 2006;34(1):8-11. 
2. Medina-Escobedo M, Zaidi M, Real-de León E, Orozco-Rivadeneyra S. Urolithiasis prevalence and risk factors in Yucatan, Mexico. Salud publica de Mexico. 2002;44(6):541-5.

3. Yap W, Belfield J, Bhatnagar P, Kennish S, Wah $\mathrm{T}$. Evaluation of the sensitivity of scout radiographs on unenhanced helical CT in identifying ureteric calculi: a large UK tertiary referral centre experience. The British journal of radiology. 2012;85(1014):800-6.

4. Croppi E, Ferraro PM, Taddei L, Gambaro G, Group GFS. Prevalence of renal stones in an Italian urban population: a general practice-based study. Urological research. 2012;40(5):517-22.

5. Osther PJS. Epidemiology of kidney stones in the European Union. Urolithiasis-Basic Science and Clinical Practice: Springer; 2013. p. 3-12.

6. Ogawa Y. Epidemiology of stone disease over a 40-year period in Japan. Urolithiasis: Springer; 2012. p. 89-96.

7. Assi Z, Platt JF, Francis IR, Cohan RH, Korobkin M. Sensitivity of CT scout radiography and abdominal radiography for revealing ureteral calculi on helical CT: implications for radiologic follow-up. American Journal of Roentgenology. 2000;175(2):333-7.

8. Zagoria RJ, Khatod EG, Chen MY. Abdominal radiography after $\mathrm{CT}$ reveals urinary calculi: a method to predict usefulness of abdominal radiography on the basis of size and CT attenuation of calculi. American Journal of Roentgenology. 2001;176(5):1117-22.
9. Jackman Sv, Potter Sr, Regan F, Jarrett Tw. Plain abdominal $\mathrm{x}$-ray versus computerized tomography screening: sensitivity for stone localization after nonenhanced spiral computerized tomography. The Journal of urology. 2000;164(2):308-10.

10. Smith RC, Levine J, Rosenfeld AT. Helical CT of urinary tract stones: epidemiology, origin, pathophysiology, diagnosis, and management. Radiologic clinics of north America. 1999;37(5):911-52.

11. Dalla Palma L, Pozzi-Mucelli R, Stacul F. Presentday imaging of patients with renal colic. European radiology. 2001;11(1):4-17.

12. Yap W, Belfield J, Bhatnagar P, Kennish S, Wah $\mathrm{T}$. Evaluation of the sensitivity of scout radiographs on unenhanced helical CT in identifying ureteric calculi: a large UK tertiary referral centre experience. The British journal of radiology. 2012;85(1014):800-6.

13. Ege G, Akman H, Kuzucu K, Yildiz S. Can computed tomography scout radiography replace plain film in the evaluation of patients with acute urinary tract colic? Acta radiologica. 2004;45(4):469-73.

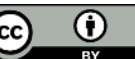

This is an Open Access article distributed under the terms of the Creative Commons Attribution License (http://creativecommons.org/licenses/by/4.0), which permits unrestricted use, distribution, and reproduction in any medium, provided the original work is properly cited. 